\title{
The copper transport-associated protein Ctr4 can form prion-like epigenetic determinants in Schizosaccharomyces pombe
}

\author{
Theodora Sideri ${ }^{1}$, Yoko Yashiroda ${ }^{2}$, David A. Ellis ${ }^{1}$, María Rodríguez-López ${ }^{1}$, Minoru Yoshida ${ }^{2}$, Mick F. Tuite ${ }^{3}$ \\ \& Jürg Bähler ${ }^{1, *}$ \\ ${ }^{1}$ University College London, Research Department of Genetics, Evolution \& Environment and Institute of Healthy Ageing, London, \\ U.K. \\ ${ }^{2}$ Chemical Genetics Laboratory, RIKEN and Chemical Genomics Research Group, RIKEN CSRS, Saitama, Japan. \\ ${ }^{3}$ Kent Fungal Group, University of Kent, School of Biosciences, Canterbury, Kent, U.K. \\ * Corresponding Author: \\ Professor Jürg Bähler, University College London, Research Department of Genetics, Evolution \& Environment, Gower Street, Darwin \\ Building; London WC1E 6BT, United Kingdom; Tel: +44(0)203-108-1602; E-mail: j.bahler@ucl.ac.uk
}

\begin{abstract}
Prions are protein-based infectious entities associated with fatal brain diseases in animals, but also modify a range of host-cell phenotypes in the budding yeast, Saccharomyces cerevisiae. Many questions remain about the evolution and biology of prions. Although several functionally distinct prion-forming proteins exist in S. cerevisiae, [HET-s] of Podospora anserina is the only other known fungal prion. Here we investigated prion-like, proteinbased epigenetic transmission in the fission yeast Schizosaccharomyces pombe. We show that $S$. pombe cells can support the formation and maintenance of the prion form of the $S$. cerevisiae Sup35 translation factor $\left[\mathrm{PSI}^{+}\right]$, and that the formation and propagation of these Sup35 aggregates is inhibited by guanidine hydrochloride, indicating commonalities in prion propagation machineries in these evolutionary diverged yeasts. A proteome-wide screen identified the Ctr4 copper transporter subunit as a putative prion with a predicted prion-like domain. Overexpression of the ctr4 gene resulted in large Ctr4 protein aggregates that were both detergent and proteinase-K resistant. Cells carrying such $\left[\mathrm{CTR}^{+}\right]$aggregates showed increased sensitivity to oxidative stress, and this phenotype could be transmitted to aggregate-free [ctr] cells by transformation with $\left[\mathrm{CTR}^{+}\right]$cell extracts. Moreover, this $\left[\mathrm{CTR}^{+}\right]$phenotype was inherited in a non-Mendelian manner following mating with naïve [ctr] cells, but intriguingly the $\left[\mathrm{CTR}^{+}\right]$phenotype was not eliminated by guanidinehydrochloride treatment. Thus, Ctr4 exhibits multiple features diagnostic of other fungal prions and is the first example of a prion in fission yeast. These findings suggest that transmissible protein-based determinants of traits may be more widespread among fungi.
\end{abstract}

\section{INTRODUCTION}

Prions were first identified as infectious amyloid forms of the mammalian protein PrP that can be transmitted from organism to organism [1]. They were subsequently shown to exist in two fungal species, Saccharomyces cerevisiae and Podospora anserina [2] and more recently in plants [3]. Animal prions are typically associated with catastrophic brain diseases such as Bovine Spongiform Encephalopathy (BSE), human Creutzfeldt-Jakob Disease (CJD) and a variety of other transmissible spongiform encephalopathies (TSEs) doi: $10.15698 / \mathrm{mic} 2017.01 .552$

Received: 30.09 .2016 ;

Accepted 20.12.2016,

Published 02.01.2017.

Keywords: yeast, prion, protein aggregation, [PSI+], meiosis, nonMendelian segregation, oxidative stress.
$[4,5]$. In each case, these fatal neurodegenerative diseases are associated with refolding of the soluble form of PrP (PrPc) into a distinct conformational state designated PrPSc. The infectious PrPSc conformer can then catalyse the refolding of other PrPc molecules into the PrPSc conformation, which over time leads to amyloid fibrils that form highly ordered aggregates with a characteristic cross $\beta$ sheet conformation [6]. These amyloid forms are also characteristic of the protein aggregates deposited in the brains of Alzheimer's, Parkinson's, and Huntington's Dis- 
ease patients. Although the potential for transmission was initially uncovered for prions, recent studies suggest the prion-like spread of a number of other amyloid-based protein aggregates in many neurodegenerative pathologies [712].

In the budding yeast $S$. cerevisiae there are at least 8 well-established examples of proteins that exhibit prionlike properties [2,13-17], and a systematic survey of the proteome has identified many more potential prionforming proteins [18]. The prion phenomenon is therefore widespread in this yeast species. The most extensively studied $S$. cerevisiae prion is $\left[P S I^{+}\right]$that is formed by the Sup35 protein, an essential translation termination factor [19-22]. Aside from S. cerevisiae, the only other fungal prion so-far established is the [Het-s] prion of the filamentous fungus, Podospora anserina [23]. In contrast to their mammalian counterparts, fungal prions do not generally kill their host, although there have been reports of prionmediated toxicity in S. cerevisiae [24-26]. In most cases, prions in S. cerevisiae actually confer a selective growth advantage in a variety of potentially detrimental environments in both laboratory-bred [20, 22, 27, 28] and nondomesticated strains [29].

Budding yeast prions share a number of properties with mammalian prions: they consist of protein aggregates resistant to detergents and proteases, most likely amyloid in nature; they are transmissible without any direct nucleic acid involvement; and overexpression of the soluble protein results in elevated de novo formation of 'infectious' prion aggregates [30]. Besides the fungal and animal prions so far identified and verified, there have also been several recent reports of prion-like mechanisms in mammalian cells [31, 32]. In fission yeast, a 'prion-like state' has been reported which allows cells to survive without calnexin and has been linked to an extrachromosomally-inherited determinant designated $\left[\mathrm{Cin}^{+}\right]$[33]. It remains to be established whether $\left[\mathrm{Cin}^{+}\right]$is a bona fide prion.

The extensive study of $S$. cerevisiae prions has provided crucial information on their mode of propagation, cellular function, and evolution and established prions as a unique class of protein-based epigenetic elements that can have a wide variety of impacts on the host [14-17, 20, 22, 29, 34, 35]. These studies have also allowed us to define molecular features of prions. All bar two of the verified prions of $S$. cerevisiae contain a discrete prion-forming domain ( $P r D)$, a region typically rich in GIn and Asn residues and which is essential for prion formation and continued propagation [2]. The exceptions lacking a typical PrD are the Mod5 protein, which confers resistance to antifungal drugs in its $\left[M O D^{+}\right]$prion state [36] and the Pma1/Std1 proteins that define the $\left[G A R^{+}\right]$prion [37]. Identification of new fungal prion-forming proteins in evolutionarily diverged species can contribute to our understanding of the structure, function and evolution of prions. Notably, while $2.7 \%$ of the budding yeast proteins are rich in Gln and Asn residues, only $0.4 \%$ and $0.9 \%$ of fission yeast and human proteins, respectively, show this characteristic. This bias raises the possibility that fission yeast will offer relevant complementary insight into human prion biology [38].
Fungal prions require specific proteins - molecular chaperones - for their propagation during cell division. In particular, the ATP-driven chaperone Hsp104 is essential for the continued propagation of prions in S. cerevisiae [39]. Hsp104 breaks aggregates to create additional lower molecular weight seeds (also known as propagons) for prion propagation [37]. The chiatropic agent guanidine hydrochloride inhibits the ATPase activity of Hsp104 leading to loss of prions during cell division [40]. Although no orthologue of Hsp104 has yet been described in mammals, an orthologue is present in S. pombe but was originally reported to be unable to substitute for the $S$. cerevisiae Hsp104 protein in propagation of the $\left[\mathrm{PSI}^{+}\right]$prion in S. cerevisiae cells [41]. A recent study, however, contradicts this finding by showing that S. pombe Hsp104 can indeed substitute for S. cerevisiae Hsp104 and propagate S. cerevisiae prions [42]. This latter study also showed that SpHsp70 (Ssa1 and Ssa2) and the Hsp70 nucleotide exchange factor Fes1 can propagate budding yeast prions, suggesting that $S$. pombe has all of the chaperone machinery used by $S$. cerevisiae to propagate the prion form of several proteins. In neither of these two studies was it established whether this chaperone machinery also plays a role in propagating endogenous prions in S. pombe.

In searching for prions in a tractable organism such as $S$. pombe, different criteria can be used to indicate whether or not a specific protein has the ability to form a transmissible prion. These criteria include: (a) overexpression of the soluble protein results in formation of mitotically transmissible aggregates of that protein; (b) the resulting aggregates can be transmitted to cells lacking the aggregates, either naturally by cell fusion (e.g. during sexual reproduction) or experimentally by protein transformation [43]; and (c) the phenotype associated with acquisition of the aggregated form of the protein is consistent with a loss of function of the corresponding protein [44].

In evolutionary history, $S$. pombe separated from $S$. cerevisiae over 400 million years ago. Analysing prion behaviour in S. pombe could therefore provide a complementary model system to study the establishment and transmission of infectious amyloids and the evolution of prions as epigenetic regulators of host cell phenotypes. Yeastbased models of human amyloidosis have already made important contributions to our understanding of these increasingly prevalent diseases $[45,46]$, but such studies have also revealed differences between the budding and fission yeast models. For example, with respect to $\alpha$ synuclein amyloids associated with Parkinson's disease, the E46K $\alpha$-synuclein mutant is toxic to $S$. pombe, but not to $S$. cerevisiae [43]. Yet $S$. pombe has been little exploited in such studies and there is a paucity of tractable model organisms to investigate prion biology. Here, we show that $S$. pombe not only has the cellular machinery to allow a heterologous prion - the $\left[\mathrm{PSI}^{+}\right]$prion from $\mathrm{S}$. cerevisiae - to form and propagate, but also has at least one endogenous protein that satisfies the key criteria to define prions with the potential to form a protein-based epigenetic determinant that can impact the phenotype of the host. 


\section{RESULTS}

Fission yeast supports formation of the budding yeast $\left[P S I^{+}\right]$prion

To test whether $S$. pombe cells can propagate the prion form of a protein, we first tested whether overexpression of the NM region (residues 1 - 254) of the $S$. cerevisiae Sup35 protein (ScSup35) fused to GFP resulted in the generation of heritable protein aggregates. Approximately $20 \%$ of cells overexpressing ScSup35 contained either one large or several smaller fluorescent foci consistent with ScSup35GFP aggregation, with the remaining cells showing diffused cellular fluorescence (Figure 1A). This result is similar to the behaviour seen when this construct is overexpressed in S. cerevisiae $\left[\mathrm{PIN}^{+}\right]$cells [47]. To establish the dependency of the observed ScSup35-GFP aggregation and transmission on Hsp104, cells overexpressing ScSup35-GFP were grown in the presence of $3 \mathrm{mM}$ guanidine hydrochloride $(\mathrm{GdnHCl})$ for 35-40 generations. This treatment completely abolished the formation of fluorescent foci with fluorescence becoming diffused in all cells (Figure 1A), indicating that the ScSup35-GFP remained soluble. This 'curing' effect of $\mathrm{GdnHCl}$ is seen with the majority of prions in S. cerevisiae [48], because their propagation is absolutely dependent on Hsp104 activity.

The finding that ScSup35-GFP formed aggregates in S. pombe cannot be taken as evidence that these aggregates act as transmissible prions. To test whether the observed aggregates show such prion-like behaviour and can establish a $\left[\mathrm{PSI}^{+}\right]$state, we co-transformed $S$. cerevisiae [psi] cells with the pRS416 yeast-centromere plasmid, together with an extract prepared from $S$. pombe cells containing ScSup35-GFP foci. Among $72 \mathrm{~S}$. cerevisiae $\mathrm{Ura}^{+}$colonies obtained after transformation, six were confirmed as $\left[\mathrm{PSI}^{+}\right]$ colonies by a $\mathrm{GdnHCl}$ elimination test (Figure 1B; Table 1). This frequency was similar to the one we obtained by cotransformation using a non-sonicated $S$. cerevisiae $\left[P S I^{+}\right]$ cell extract into the same [psi] S. cerevisiae cells (Table 1). Co-transformation with a cell extract prepared from [psi] S. cerevisiae cells or a S. pombe wild-type cell extract gave no $\left[\mathrm{PSI}^{+}\right]$colonies (Table 1). Moreover, extracts prepared from S. pombe cells containing ScSup35-GFP aggregates, grown

TABLE 1. Number of $\left[\mathrm{PSI}^{+}\right] \mathrm{Ura}^{+} \mathrm{S}$. cerevisiae colonies after transformation with cell-free extracts prepared from different species and strains as indicated.

\begin{tabular}{lcc}
\hline Cell-free extract source & $\begin{array}{c}\text { Total Ura }^{+} \\
\text {colonies }\end{array}$ & $\begin{array}{c}{\left[\mathrm{PSI}^{+}\right]} \\
\text {colonies }\end{array}$ \\
\hline$S c[p s i]$ & 75 & 0 \\
\hline$S c\left[P S I^{+}\right]$ & 84 & 7 \\
\hline$S p$ wild-type & 88 & 0 \\
\hline$S p$ pREP41-ScSup35-GFP & 72 & 6 \\
\hline $\begin{array}{l}\text { Sp pREP41-ScSup35-GFP, } \\
\text { GdnHCl treated }\end{array}$ & 98 & 0 \\
\hline
\end{tabular}

Sc: S. cerevisiae; Sp: S. pombe
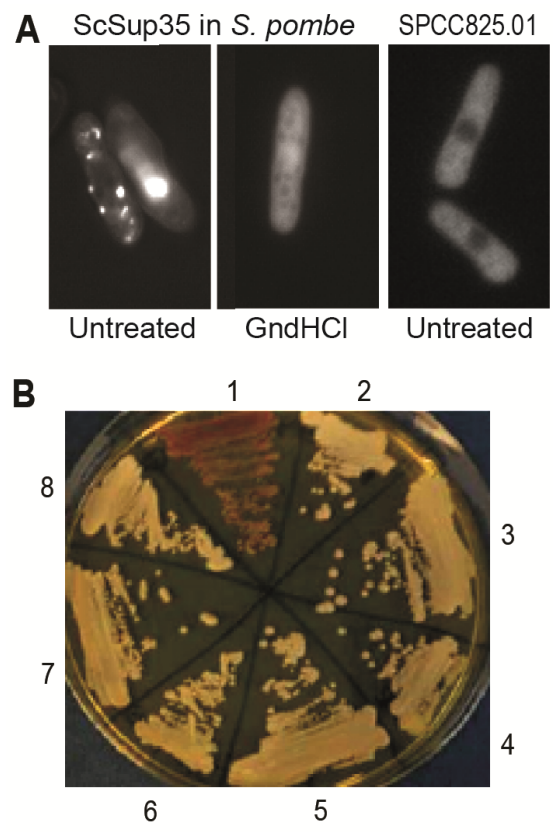

FIGURE 1: Fission yeast can support formation and propagation of the budding yeast $\left[\mathrm{PSI}^{+}\right]$prion. (A) Left: Fluorescent foci in S. pombe resulting from overexpression of S. cerevisiae Sup35-GFP, using the medium-strength, regulatable nmt41 promoter under activating conditions from a high-copy plasmid. This result resembles the patterns seen when ScSup35-GFP is overexpressed from a high-copy plasmid in S. cerevisiae [47]. Middle: The foci are absent from cells grown for 35-40 generations in 3 mM guanidine hydrochloride (GndHCl). Right: Most GFP-tagged S. pombe proteins do not show fluorescent foci when overexpressed (see also [54]); the uncharacterized protein SPCC825.01(predicted ATPase) serves as an example for such a negative control, showing diffuse cytoplasmic localization. (B) Transformation of $S$. pombe cell extract containing ScSup35-GFP aggregates can convert S. cerevisiae [psi'] cells (red, streak 1 ) to $\left[P S I^{+}\right]$cells (white, streaks 2-4 and 6-8). Streaks 1 and 5 show control [psi] and [PSI $\left.{ }^{+}\right]$ strains, respectively.

in the presence of $3 \mathrm{mM} \mathrm{GdnHCl}$ for at least 30 generations, gave no $\left[\mathrm{PSI}^{+}\right]$transformants (Table 1 ), suggesting that inhibition of S. pombe Hsp104 prevents the establishment of the transmissible ScSup35-GFP aggregates in S. pombe. These results lead us to conclude that fission yeast contains the molecular machinery required for the formation of the $\left[\mathrm{PSI}^{+}\right]$prion with Hsp104 playing an essential role.

\section{Search for prion candidates in fission yeast}

To search for endogenous $S$. pombe proteins that might show prion-like features, we compiled a list of 80 candidate prions based on two sources: proteins identified by mass spectrometry to be insoluble and detergent resistant in $\left[\mathrm{Cin}^{+}\right]$cells, and $\mathrm{Q} / \mathrm{N}$-rich proteins identified bioinformatically [38]. These candidate proteins were then experimentally tested for prion-like features using a range of assays: 1) overexpression of fluorescently tagged proteins to test for distinct cellular foci; 2) induction of lasting phenotypes upon transient protein overexpression with 40 different environmental and stress conditions being tested; and 3) 
inheritance of induced phenotypes in a non-Mendelian manner. Unfortunately, none of the 80 candidate proteins showed positive results in all three of these assays and no protein seemed therefore sufficiently promising to further pursue.

After these initial attempts leading to negative results, we applied the PLAAC algorithm that accurately predicts PrDs based on the extensive sequence and functional data from S. cerevisiae prion-forming proteins [49]. A PLAAC screen of the entire fission yeast proteome identified 295 proteins that contained putative PrDs (Supplemental Table 1). Two of these proteins, Fib1 and Myo1, were included among the 80 candidate proteins used in the initial screen. We looked for enriched features among these proteins using the AnGeLi tool [50]. The 295 proteins were strongly enriched for Ser, Pro, Asp and Thr residues $\left(p \sim 9.9 \times 10^{-12}\right.$ to 0.002 ) and under-enriched for Lys, Leu, Ile and Glu residues ( $p \sim 7.5 \times 10^{-10}$ to 0.001 ). Moreover, these proteins were enriched for features diagnostic of plasma membrane and cell surface proteins, including the Pfam domain 'Ser-Thr- rich glycosyl-phosphatidyl-inositol-anchored membrane family' ( $p$ 0.0009), GPI anchor surface proteins ( $p$ $\sim 0.0007$ ), and the GO cellular component 'anchored component of external side of plasma membrane' and related categories $(p<0.004)$.

We performed some initial in vivo tests on 30 proteins with high PLAAC scores to identify the most promising prion candidates. Following overexpression of the respective proteins, the cells were subject to a variety of analyses, including assaying an array of growth phenotypes and were also screened for the presence of detergent-resistant forms of the protein using semi-denaturing detergent agarose gel electrophoresis (SDD-AGE).

Ctr4 contains predicted prion-forming domain in disordered region

Based on these preliminary analyses, we focused on the Ctr4 copper transporter protein which contains one strongly predicted 55 amino-acid PrD (residues 55-109), consisting of 10 Asn but no Gln residues (Figure $\mathbf{2 A}$ ). Notably, this
A

MSFFSAAKQS LGNSLIKLGT SMAQNSQGPV DDSSLSQLEN LLPPLQILTA RAAMAAMNMS NDTSMSGMNM TNSTTPMSGM PrD NMTINSTTSMS GMNMSNSTTS MSGMNMTNTT TTAKASSCKL SMYWNWYTID ACFITKHWHI TSKHMFVGSI FGIIFMMMAL ELVRRGQREF DRWCVRRFSP A.SNSCCHSGA PVHSGPSMAL RIFLHFLRSC FYLVQYIVAY IAMLLAMYYN GYVILFLFCG TFFGYFLFGA DTISTKASSS VQTKTIVQVA DEKHEHDSSQ YSDTTPTTE

C

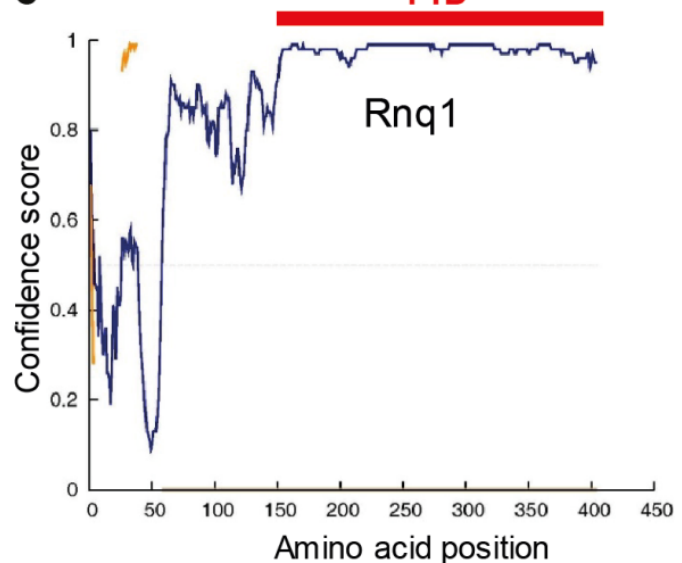

B
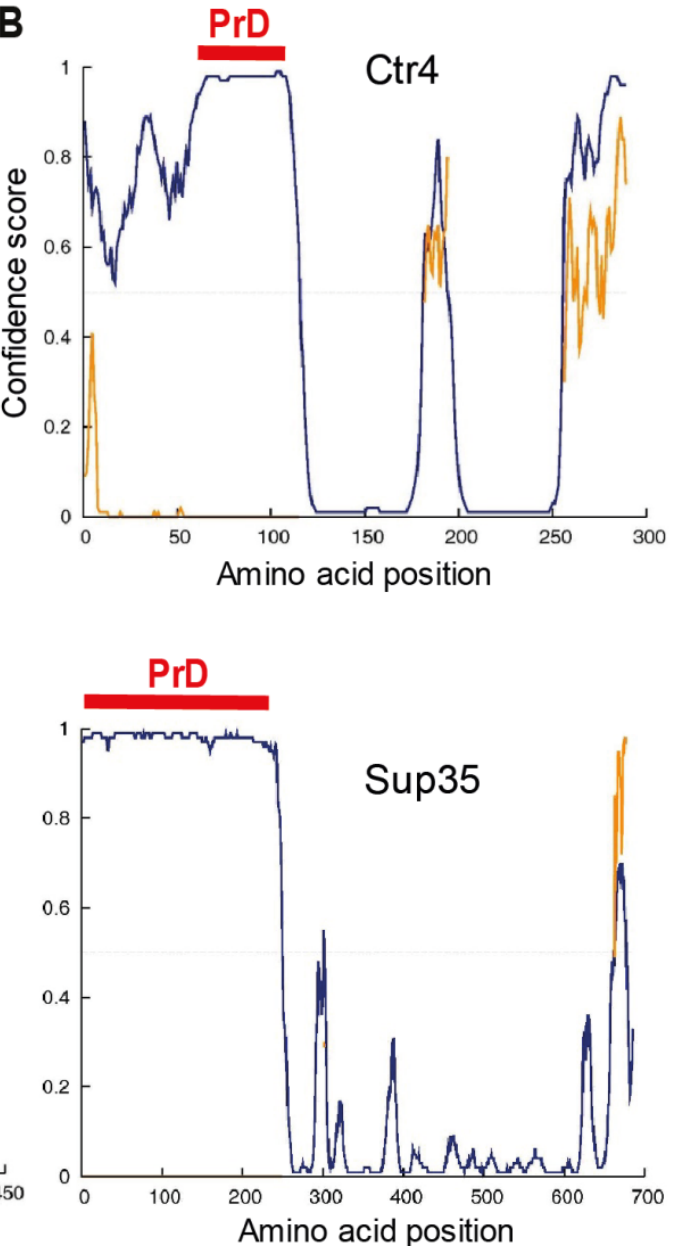

FIGURE 2: Sequence features of Ctr4 (A) The 289 amino acid Ctr4 protein contains a 55 amino acid prion-forming domain (PrD, red) as predicted by the PLAAC algorithm [49]. (B) The predicted PrD of Ctr4 (red bar) coincides with the highest predicted unfolded region (disordered, blue curve) according to the DISOPRED3 algorithm [51]. The yellow trace is the location of predicted protein binding sites within disordered regions. (C) DISOPRED3 predictions of intrinsically disordered regions in two prion-forming proteins of S. cerevisiae, Rnq1 (left) and Sup35 (right), together with the locations of the experimentally defined PrDs, as in (B). 
PrD exactly maps onto an intrinsically disordered region of the protein as predicted by the DISOPRED3 program [51] which identifies residues likely to be natively unfolded (Figure 2B). A similar analysis with two established prionforming proteins of S. cerevisiae, namely Sup35 and Rnq1, shows that in both cases a predicted highly disordered region maps to the predicted and functionally defined PrDs of these proteins (Figure $\mathbf{2 C}$ ).

\section{Ctr4 forms proteinase-resistant polymers}

To establish whether $\mathrm{Ctr} 4$ could switch to a transmissible aggregated state expected for a prion, we first asked whether overexpression of $\mathrm{Ctr} 4$ generated aggregates that were resistant to proteinase $\mathrm{K}(\mathrm{PK})$ degradation and to detergents such as sodium dodecyl sulphate (SDS) [52, 53]. $\mathrm{Ctr} 4$ was overexpressed using the $n m t 1$ promoter driving a full-length genomic copy of ctr4 fused to YFP, using the corresponding strain from the $S$. pombe ORFeome collection [54]. Unlike for ScSup35-GFP (Figure 1A), overexpressed Ctr4-YFP did not form distinct cytoplasmic foci, but rather localised to the cell periphery, although Ctr4 clusters and ribbon-like patterns were also evident (Figure 3A; [54]). This result is in contrast to Ctr4-GFP expressed at lower levels which localizes more evenly to the cell periphery [55].

We explored whether Ctr4-YFP in these cells existed in a different conformational state. Hence extracts from ex-
A

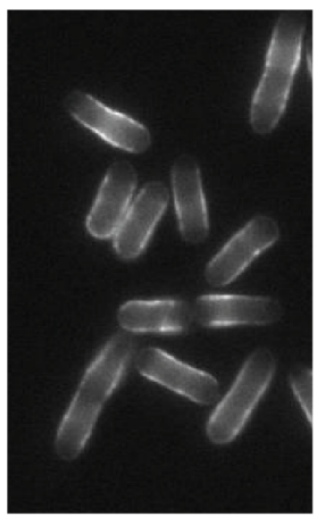

C

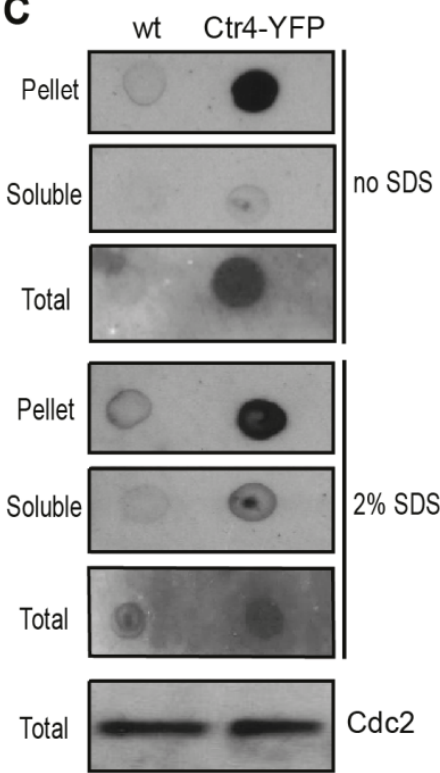

B
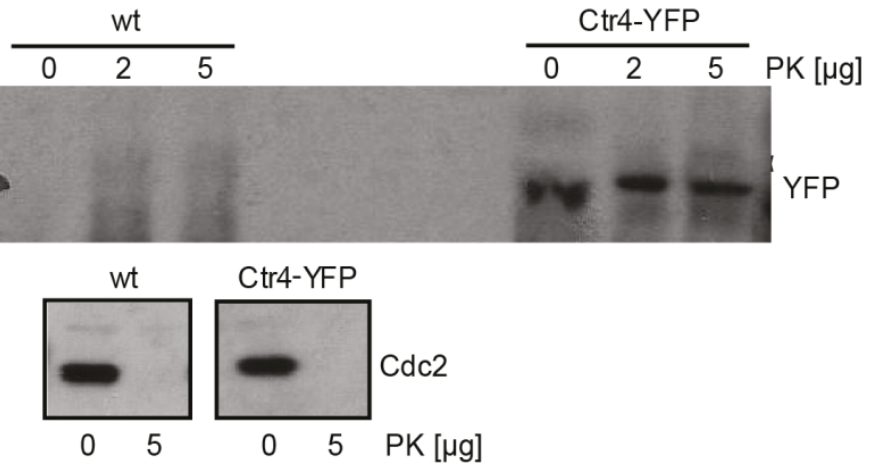

D

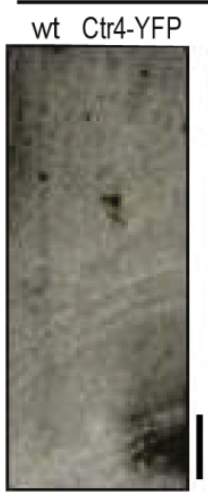

RT

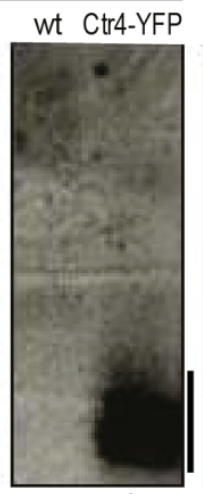

cured

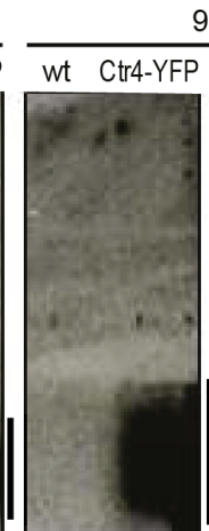

non cured $95^{\circ} \mathrm{C}$

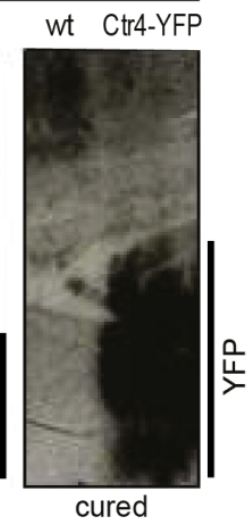

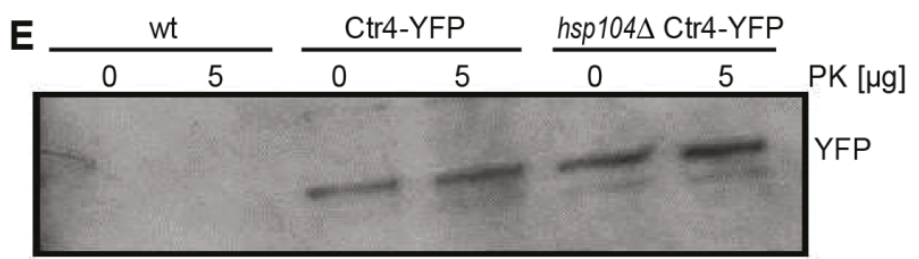

FIGURE 3: Ctr4 exhibits properties consistent with prion formation. (A) Fluorescence micrograph of cells overexpressing Ctr4-YFP, showing localization and aggregation of Ctr4 at cell periphery. (B) Extracts from wild-type (wt) cells, expressing native Ctr4, and cells overexpressing Ctr4-YFP, treated without (0) or with 2 or $5 \mu$ g proteinase K (PK) were run by SDS-PAGE followed by western blotting using anti-GFP and anti-Cdc2 antibodies to detect Ctr4 and Cdc2 (loading control), respectively. (C) Dot plots with extracts from wild-type (wt) cells and cells overexpressing Ctr4-YFP using anti-GFP antibodies to detect YFP. Results for pellet, soluble and total cell fractions are shown as indicated, both with and without pre-treatment of the nitrocellulose membranes with $2 \%$ SDS. Bottom: SDS-PAGE of the same extracts to detect Cdc2 as a loading control. (D) SDD-AGE gels of samples treated at room temperature (RT) and at $95^{\circ} \mathrm{C}$, both with and without curing with $\mathrm{GdnHCl}$ as indicated. Overexpressed Ctr4-YFP forms high-molecular weight protein aggregates (right lanes); heat treatment and curing did not abolish the high-molecular weight species of $\mathrm{Ctr} 4$, but led to a larger range in aggregate sizes. (E) Extracts from wild-type (wt) cells, cells overexpressing Ctr4-YFP and hsp104 deletion cells overexpressing Ctr4-YFP, treated without or with $5 \mu \mathrm{g}$ PK were run by SDS-PAGE followed by western blotting using anti-GFP antibody to detect YFP. 
ponentially growing cells overexpressing Ctr4-YFP were treated with PK as described in Materials and Methods, followed by western analysis using an anti-GFP antibody. No or little degradation of Ctr4-YFP by PK was observed in these cell extracts, while $\mathrm{Cdc} 2$, a protein not predicted by PLAAC to show prion-like features, was fully degraded by PK (Figure 3B). These findings suggest that Ctr4-YFP was indeed in an altered conformational state.

The resistance of the overexpressed Ctr4-YFP to SDS was further assessed using a dot blot assay that has been widely used to analyse disease-associated amyloids [56]. First, differential centrifugation was used to fractionate cell-free extracts prepared from cells overexpressing Ctr4YFP. The resulting insoluble extract (pellet fraction), together with the soluble and unfractionated extracts, were spotted onto nitrocellulose membranes, with or without treatment with $2 \%$ SDS for $10 \mathrm{~min}$ at room temperature. The bulk of the Ctr4-YFP in these strains was detected in the pellet fraction, and this signal remained strong even following treatment with $2 \%$ SDS (Figure 3C). These data are consistent with the Ctr4-YFP forming detergent resistant aggregates when overexpressed.

To further explore the nature of the altered conformational form of Ctr4, we exploited semi-SDD-AGE, a method commonly used to detect high-molecular weight, detergent resistant prion aggregates in S. cerevisiae [57]. We analyzed cell extracts from control and Ctr4 overexpressing cells by SDD-AGE. High-molecular weight protein polymers were only evident in cells overexpressing Ctr4-YFP, and these aggregates were resistant to heat treatment at $95^{\circ} \mathrm{C}$ (Figure 3D). Taken together, these results show that overexpression of Ctr4 results in proteinase- and detergentresistant protein polymers, consistent with $\mathrm{Ctr} 4$ being able to form prion-like structures in vivo.

\section{Hsp104 is not required for the formation or propagation of Ctr4 aggregates}

We next investigated whether the S. pombe orthologue of Hsp104 (SpHsp104) is necessary for formation and/or propagation of the Ctr4-YFP aggregates in S. pombe. In contrast to most budding yeast prions [58], growth of Ctr4overexpressing cells in the presence of $3 \mathrm{mM} \mathrm{GdnHCl}$, an inhibitor of Hsp104 ATPase activity, did not abolish Ctr4 polymer formation as judged by SDD-AGE (Figure 3D). Furthermore, both heat and $\mathrm{GdnHCl}$ treatment increased the size ranges of the Ctr4-YFP aggregates formed (Figure 3D).

These results might reflect that $\mathrm{SpHsp104}$ is resistant to $\mathrm{GdnHCl}$ as has been reported for the C. albicans Hsp104 [59], although the finding that the formation of a heterologous prion was blocked by $\mathrm{GdnHCl}$ treatment suggests otherwise (Figure 1A). To unequivocally define the role of SpHsp104, we deleted the hsp104 gene from the Ctr4-YFP overexpression strain and repeated the test for PKresistance of the protein after growing cells for at least 80 generations. Ctr4-YFP remained resistant to PK even in the absence of Hsp104 (Figure 3E). This finding indicates that the acquisition of PK-resistant forms of Ctr4-YFP does not require $\mathrm{Hsp} 104$, consistent with the result that $\mathrm{GdnHCl}$ did not eliminate Ctr4-YFP aggregation (Figure 3D). These results therefore suggest that $\mathrm{SpHsp104}$ is not required for Ctr4-YFP aggregation, and raise the possibility that another cellular chaperone may be required for the propagation of the aggregated form of Ctr4-YFP.

\section{Ctr4 overexpression results in heritable sensitivity to oxi- dative stress}

Prion-forming proteins in S. cerevisiae impact on a wide range of phenotypes when they take up their prion form, often reflecting a loss of function [60]. To investigate whether the conformational change seen in cells overexpressing Ctr4 resulted in an altered phenotype, we assayed the growth of the overexpression strain under heavy metal, heat and oxidative stress. While no changes were observed in response to stresses induced by cobalt and heat shock for example (data not shown), the strain did show an increased sensitivity to $2 \mathrm{mM}$ hydrogen peroxide, an inducer of oxidative stress [61].

To quantify the effects of oxidative stress, we first determined the ratio of the maximum growth rates for the overexpression strain in $\mathrm{H}_{2} \mathrm{O}_{2}$ vs control medium. This ratio decreased $\sim 4.5$ to 7 -fold for cells overexpressing Ctr4 compared to the wild-type cells (Figure 4A), suggesting that Ctr4 overexpression leads to increased sensitivity to oxidative stress. This phenotype was retained even after the cells were grown in $3 \mathrm{mM} \mathrm{GdnHCl}$ for at least 30 generations (data not shown). The $\mathrm{H}_{2} \mathrm{O}_{2}$ sensitivity of cells overexpressing $\mathrm{Ctr} 4$ was also confirmed by determining the viability of exponentially growing cultures exposed to $\mathrm{H}_{2} \mathrm{O}_{2}$ for $24 \mathrm{~h}$ (Figure 4B). In this assay, wild-type cells showed viabilities ranging from $74.7-89.7 \%$ compared with $62.2-82.0 \%$ for the Ctr4 overexpressing cells. Furthermore, serial dilution spotting assays on agar plates with and without $\mathrm{H}_{2} \mathrm{O}_{2}$ also revealed sensitivity to oxidative stress for cells overexpressing Ctr4 (Figure 5).

The increased sensitivity to oxidative stress upon overexpression of $\mathrm{Ctr} 4$ suggests that $\mathrm{Ctr} 4$ is inactivated under this condition. In S. pombe, high-affinity copper uptake is carried out by a heteromeric complex of Ctr4 and Ctr5 [62]. We therefore tested whether $\operatorname{ctr} 4 \Delta$ single and $\operatorname{ctr} 4 \Delta \operatorname{ctr} 5 \Delta$ double mutants also showed sensitivity to oxidative stress. As ctr4 $\triangle$ mutants grew very slowly on YES medium, we performed this assay on EMM medium, on which the Ctr4 overexpressing cells grew somewhat slower (Figure 4C, left). Both the $c t r 4 \Delta$ single and $c \operatorname{tr} 4 \Delta \operatorname{ctr} 5 \Delta$ double mutants and the Ctr 4 overexpressing cells showed increased sensitivity to oxidative stress compared to wild-type cells (Figure $4 \mathrm{C}$, right). This result indicates that $\mathrm{Ctr} 4$ overexpression leads to loss of Ctr4 function.

A key property of any prion-mediated phenotype is that it can be transmitted to naïve cells by transfer of the altered conformational form. We therefore investigated whether the increased sensitivity to $\mathrm{H}_{2} \mathrm{O}_{2}$ in cells overexpressing $\mathrm{Ctr} 4$ was transmissible to other cells using protein transformation. Cell-free extracts were prepared from wild-type and Ctr4 overexpressing cells and high molecular weight 'insoluble' fractions of these extracts co-trans- 


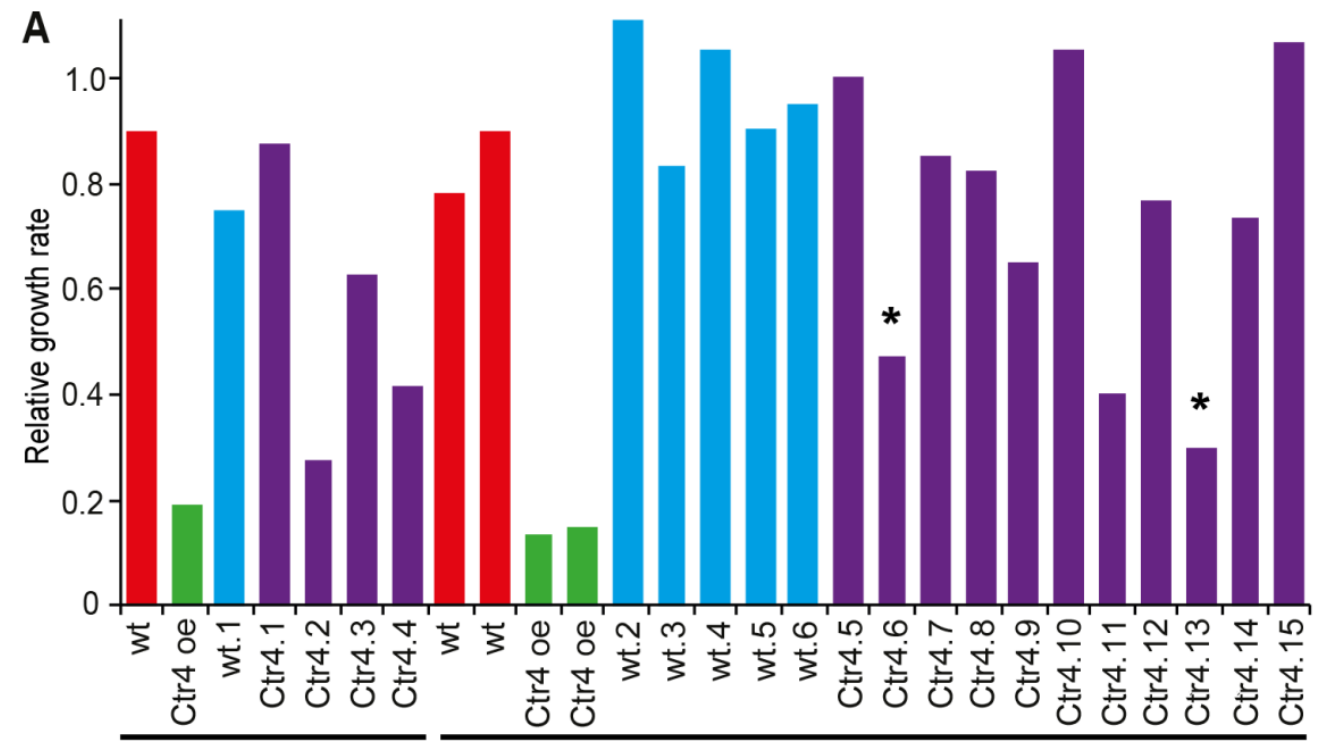

Experiment 1
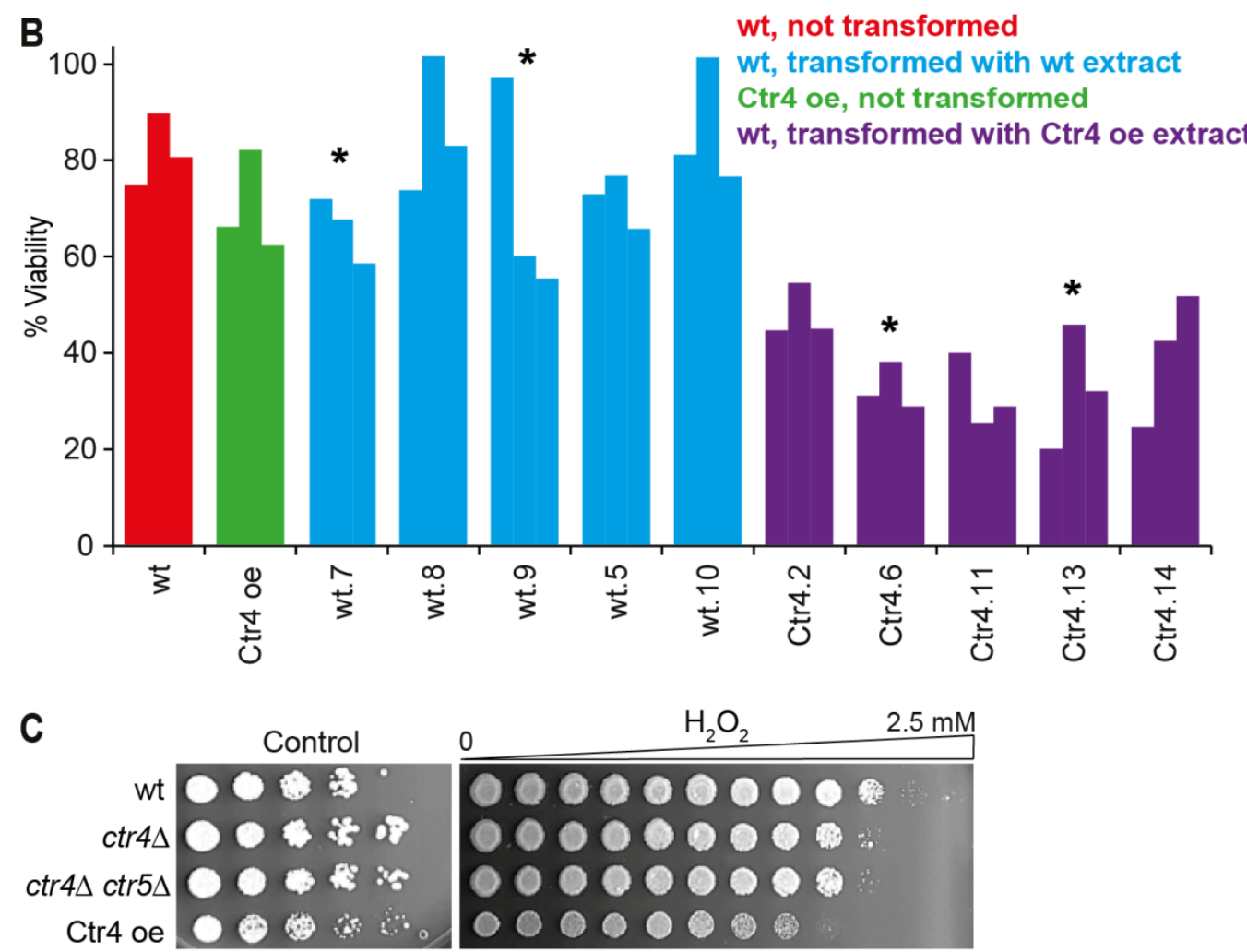

FIGURE 4: Ctr4 overexpression leads to $\mathrm{H}_{2} \mathrm{O}_{2}$ sensitivity which is transmissible by protein transformation. (A) Left, Experiment 1: wild-type cells were transformed with a cell-free extract from wild-type (wt.1) and Ctr4 overexpressing cells (Ctr4.1-Ctr4.4). For all strains, the ratios of maximum growth rate in liquid medium with $1 \mathrm{mM} \mathrm{H}_{2} \mathrm{O}_{2}$, relative to maximum growth rate in untreated medium, were determined in a Biolector microfermentor. Data for control wt and Ctr4 overexpression (Ctr4 oe) cells are also shown. Right, Experiment 2: as Experiment 1, but showing additional, independent transformants with extracts from wild-type (wt.2-wt.6) and Ctr4 overexpressing cells (Ctr4.5-Ctr4.15). Data for two independent wild-type control (wt) and two independent Ctr4 overexpression (Ctr4 oe) cells are also shown. Strains whose extracts were used for the protein transformations in the meiosis experiments (Figure 5) are indicated with asterisks. (B) Wild-type cells were transformed with extracts from wild-type (wt.5, wt.7-wt.10) or Ctr4 overexpressing cells (Ctr4.2. Ctr4.6, Ctr4.11, Ctr4.13, Ctr4.14). Cell viability after treatment with $0.5 \mathrm{mM} \mathrm{H}_{2} \mathrm{O}_{2}$ relative to untreated cells was determined for the transformed strains and for control wt and Ctr4 overexpression (Ctr4 oe) strains. Strains whose extracts were used for the protein transformations in the meiosis experiments (Figure 5) are indicated with asterisks. (C) Wild-type (wt), ctr4 $\Delta$ single and $c t r 4 \Delta \operatorname{ctr} 5 \Delta$ double mutants, and Ctr4 overexpressing cells were spotted in serial dilutions on EMM plates (Control, left) or in equal quantities onto EMM plates containing a gradient of 0 to $2.5 \mathrm{mM} \mathrm{H}_{2} \mathrm{O}_{2}$ (right). 
formed into wild-type naïve cells as described in Materials and Methods. The growth of eleven independently-derived transformed colonies in the presence of $\mathrm{H}_{2} \mathrm{O}_{2}$ was evaluated alongside a control strain and a strain overexpressing Ctr4 (Figure 4A). Eight out of 15 wild-type colonies transformed with $\mathrm{Ctr} 4$ overexpression extracts became more sensitive to $\mathrm{H}_{2} \mathrm{O}_{2}$ compared to wild-type colonies transformed with wild-type extracts. Such protein transformation with $S$. cerevisiae prions rarely generates $>50 \%$ prion transformants [20]. Similar results were obtained using the viability assay: transformation with extracts from cells overexpressing Ctr4 typically led to increased sensitivity to oxidative stress as shown in Figure 4B. Thus, wild- type cells transformed with an insoluble fraction of cells overexpressing Ctr4, which contains high molecular weight polymers of $\mathrm{Ctr} 4$ resistant to SDS and PK (Figure 3 ), often become sensitive to $\mathrm{H}_{2} \mathrm{O}_{2}$. We therefore conclude that the phenotype caused by $\mathrm{Ctr} 4$ overexpression is transmissible between cells, consistent with Ctr4 acting as a prion.

\section{Ctr4-dependent sensitivity to oxidative stress is inherited in a non-Mendelian manner}

Yeast prions and other cytoplasmic genetic determinants are inherited in a non-Mendelian manner during meiosis. Our finding that the sensitivity to $\mathrm{H}_{2} \mathrm{O}_{2}$ caused by $\mathrm{Ctr} 4$ overexpression can be transmitted to wild-type cells by
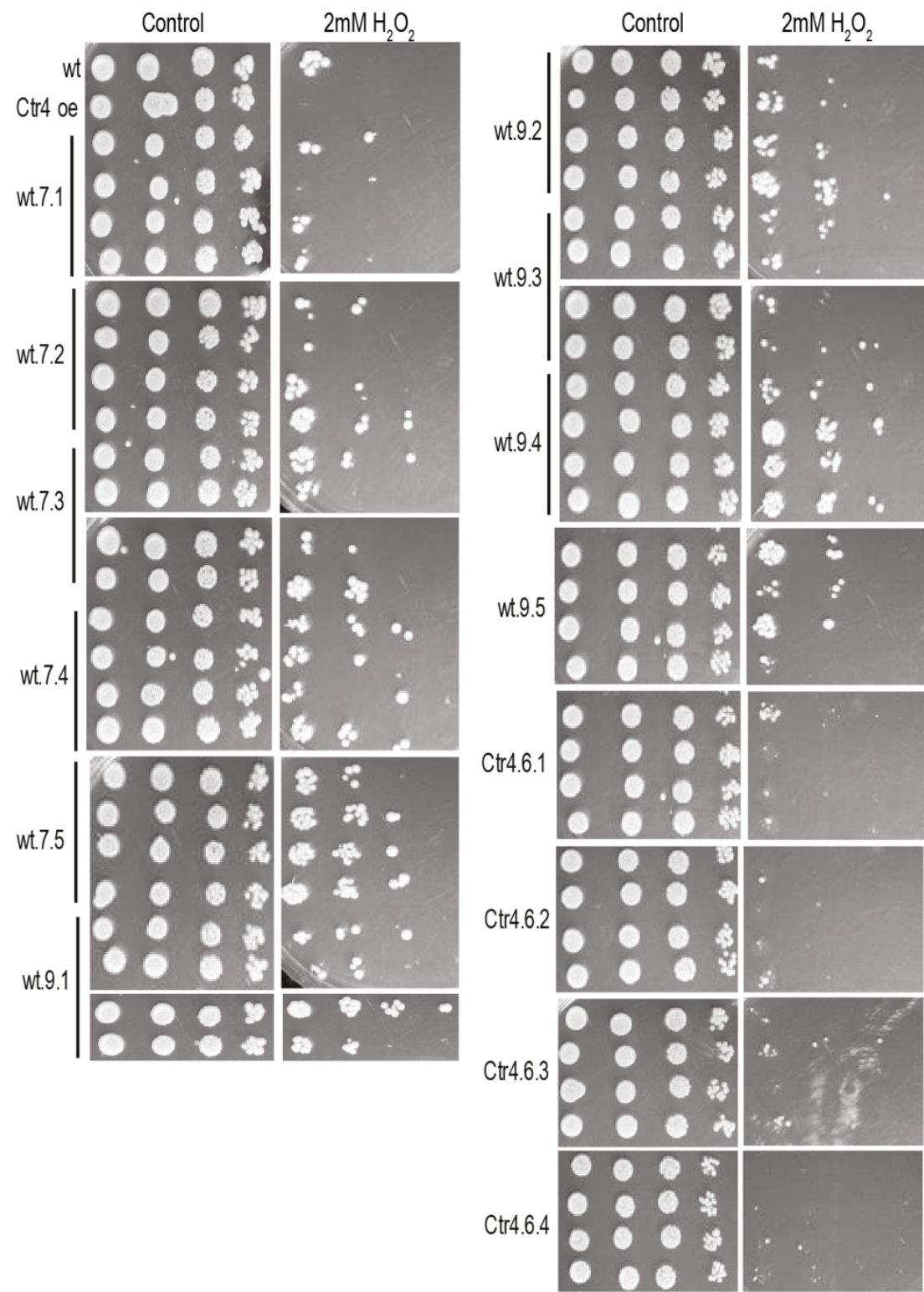

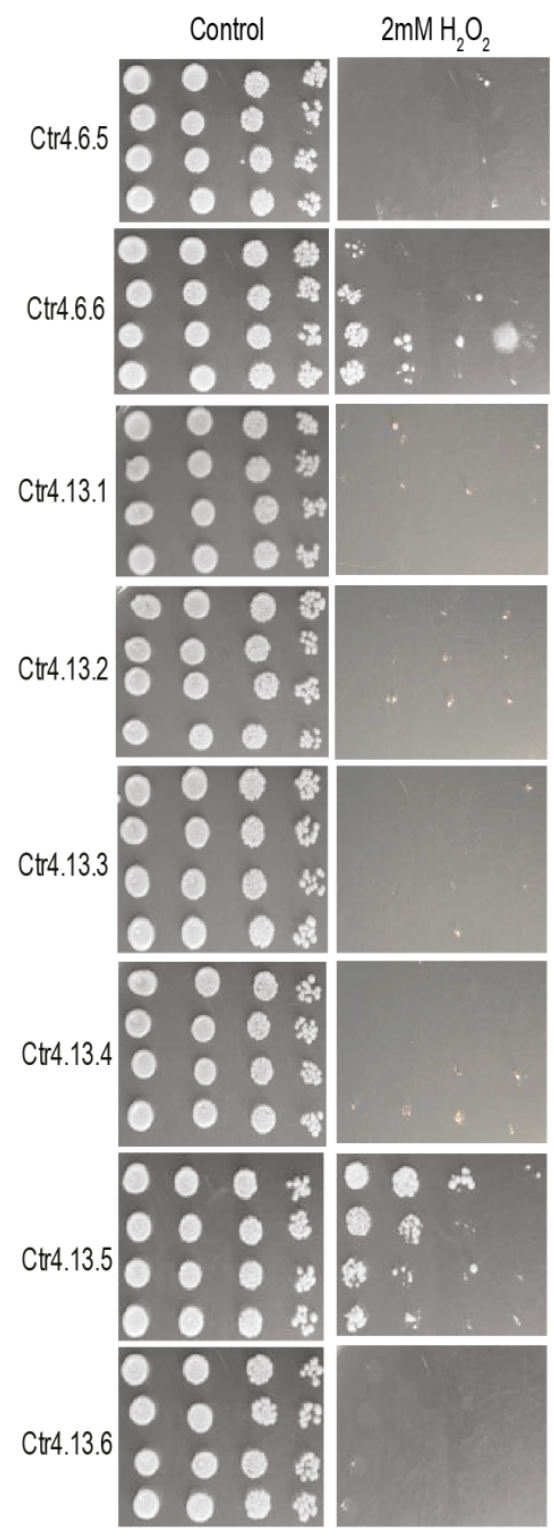

FIGURE 5: Sensitivity to $\mathrm{H}_{2} \mathrm{O}_{2}$ due to $\mathrm{Ctr} 4$ overexpression is inherited in a non-Mendelian manner. Wild-type (wt) cells transformed with extract from wild-type or Ctr4 overexpressing cells (indicated with asterisks in Figure 4) were mated with wild-type cells. The four segregants from 10 tetrads involving wild-type transformants and from 12 tetrads involving Ctr4 transformants were spotted in serial dilutions onto YES plates without (control) and with $2 \mathrm{mM} \mathrm{H}_{2} \mathrm{O}_{2}$. Five or six full tetrads from each cross involving the wt.7, wt.9, Ctr4.6, Ctr4.13 transformants were examined. All plates shown have been grown together for the same times and using the same batches of media. 
protein transformation is consistent with this feature. To directly check for non-Mendelian inheritance, we examined two strains, designated Ctr4.6 and Ctr4.13 that showed the sensitivity to $\mathrm{H}_{2} \mathrm{O}_{2}$ phenotype and two control strains, wt.7 and wt.9 (Figure 4, asterisks). We mated each of these four strains with the wild-type strain and dissected four spores from the resulting tetrads. Each resulting spore clone was tested for sensitivity to $\mathrm{H}_{2} \mathrm{O}_{2}$ by serial dilution on agar plates. Five or six tetrads from each cross were tested (Figure 5). Analysis of the products of meiosis for both crosses involving the $\mathrm{Ctr} 4.6$ and $\mathrm{Ctr} 4.13$ strains revealed an increased $\mathrm{H}_{2} \mathrm{O}_{2}$ sensitivity in the majority of tetrads ( 10 out of the 12 tetrads examined), resulting in all four spores showing the $\mathrm{H}_{2} \mathrm{O}_{2}$ sensitive phenotype. The control strains largely resulted in spore colonies showing $\mathrm{H}_{2} \mathrm{O}_{2}$ sensitivities similar to wild-type (Figure 5). These results show that the increased sensitivity to oxidative stress due to Ctr4 overexpression segregates in a non-Mendelian manner, to all four spores resulting from a meiotic division. Moreover, the results confirm that meiotic products that do not contain the integrated Ctr4-YFP construct, can nevertheless maintain the Ctr4-specific phenotype. This finding is expected for a cytoplasmically-transmitted trait and is characteristic of prions in budding yeast. We designate this transmissible element at $\left[\mathrm{CTR}^{+}\right]$in keeping with the nomenclature used for $S$. cerevisiae prions.

\section{DISCUSSION}

Mammalian prions can cause neurodegenerative diseases, whereas fungal prions can be detrimental, beneficial or have no apparent impact on the host cell $[2,63,64]$. It is likely that prions are more widespread than currently appreciated, and that they can act as protein-based epigenetic elements allowing cells to acquire new traits in specific conditions such as stress. So far, prions have only been identified in two fungal species ( $S$. cerevisiae, $P$. anserina) and in mammals, although there is recent evidence to suggest that they may also exist in plants [3]. Although a prion-like state has been reported in fission yeast that allows cells to survive in the absence of the essential chaperone calnexin, the responsible protein(s) that determine this phenotype remain to be identified [65]. So far no other prion-like epigenetic determinants have been reported in fission yeast.

S. pombe, which is only remotely related to $S$. cerevisiae, encodes the full repertoire of the molecular chaperones that are required for prion propagation in $S$. cerevisiae, and as we show here, can form and propagate the $S$. cerevisiae $\left[\mathrm{PSI}^{+}\right]$prion. Thus, $S$. pombe contains the molecular machinery required for the formation and propagation of this heterologous prion. On the other hand, a previous study has shown that expression of the S. pombe Sup35 Nterminal region fused to the $S$. cerevisiae C-terminal domain of Sup35 does not lead to $\left[\mathrm{PSI}^{+}\right]$formation in S. cerevisiae [66], suggesting that the prion-forming ability of Sup35 is not conserved in S. pombe or that the prionforming domain is not at the $\mathrm{N}$ terminus of the protein.
In a proteome-wide screen, we have identified the $S$. pombe Ctr4 protein that, when overexpressed, can form a heritable, conformationally distinct protein with all of the required characteristics of a prion that leads to a trait we have designated as $\left[C T R^{+}\right]$. Ctr4 normally functions as a subunit for a copper transporter complex [62, 67-69], and deletion of ctr4 has been associated with sensitivity to the iron chelator ferrozine and to the DNA damaging agents 4nitroquinoline $\mathrm{N}$-oxide and hydroxyurea $[55,70]$.

Ctr4 is predicted to contain a PrD according to the PLAAC algorithm [49], and this PrD coincides with the highest predicted unfolded (disordered) region according to the DISOPRED3 algorithm [51]. To test the ability of Ctr4 to switch to and propagate as a prion we applied criteria used for $S$. cerevisiae prions. First, overexpression of $\mathrm{Ctr} 4$ as an YFP fusion resulted in $\mathrm{Ctr} 4$ clusters and ribbon-like patterns at the cell periphery, in contrast to Ctr4-GFP expressed at lower levels which localizes more evenly to the cell periphery [55]. Second, overexpression of Ctr4 resulted in the formation of pelletable aggregates that were resistant to exposure to both detergent (SDS) and protease (proteinase K). Third, overexpression of $\mathrm{Ctr} 4$ resulted in a $\mathrm{H}_{2} \mathrm{O}_{2}$ sensitivity phenotype that could be transmitted to naïve cells by protein transformation. Fourth, the $\mathrm{H}_{2} \mathrm{O}_{2}$ sensitivity [CTR ${ }^{+}$] phenotype was inherited in a non-Mendelian manner during meiosis in crosses with naïve [ctr] cells, a behaviour also seen with prions in S. cerevisiae.

Conflicting evidence exists in the literature about the effectiveness of $S$. pombe Hsp104 in facilitating budding yeast prion propagation $[41,42]$. We find that $\mathrm{GdnHCl}$ abolished ScSup35 aggregate formation and prion 'infectivity' in S. pombe, suggesting that the S. pombe Hsp104 can propagate $S$. cerevisiae $\left[\mathrm{PSI}^{+}\right]$. On the other hand, S. pombe Hsp104 was not required for maintenance and propagation of the $\left[C T R^{+}\right]$prion. This result raises the question that if Hsp104 is not required for the propagation of $\left[C T R^{+}\right]$, what chaperones are? There is at least one prion in S. cerevisiae which does not require Hsp104, i.e. [GAR $\left.{ }^{+}\right]$which leads to cellular resistance to glucose-associated repression of alternative carbon sources [37]. In the case of [GAR ${ }^{+}$, one of the Hsp70 family of chaperones (Ssa1) is absolutely required for its propagation [37, 71], while members of the Hsp40 and Hsp70 families are known to contribute to the propagation of various other yeast prions [72]. It remains to be established which S. pombe chaperone(s) - if any are required to propagate $\left[C T R^{+}\right]$in $S$. pombe. Notably, a recent study reports that $\sim 1 \%$ of the budding yeast proteins can exert prion-like patterns for inheriting biological traits; these proteins are non-amyloid but feature large intrinsically disordered domains, and the transmission of many of these proteins does not depend on Hsp104 [73, 74].

Why might $\left[C T R^{+}\right]$formation cause sensitivity to oxidative stress? Ctr4 is a high affinity copper transporter, and copper is an essential co-factor for enzymes involved in critical cellular processes including protection from oxidative stress [55]. Most prions lead to loss of function for the corresponding proteins [2], and it is therefore plausible that the $\left[\mathrm{CTR}^{+}\right]$prion compromises the supply of sufficient 
copper which is required for enzymes involved in the oxidative stress response. Consistent with this view, we find that deletion of ctr4 also leads to increased sensitivity to oxidative stress.

Among the 295 S. pombe proteins with predicted PrDs, other promising candidates include Sol1, Cyc8 and Sup35, each of which has a $S$. cerevisiae orthologue that forms prions [2]. Several S. pombe nucleoporins similar to the $S$. cerevisiae Nup100 prion [75] also contain a PrD. On the other hand, while there is no direct orthologue of Ctr4 in $S$. cerevisiae, neither of the two $S$. cerevisiae proteins that share domains with $\mathrm{Ctr} 4$, i.e. Ctr1 and Ctr3, show any prion-like sequences or properties. Moreover, unlike for $S$. pombe Ctr4, a DISOPRED3 analysis [51] did not reveal any extended stretches of disordered regions for $S$. cerevisiae Ctr1 or Ctr3 (not shown). It is likely that S. pombe contains more prion-forming proteins. By further investigating the biology of prions in fission yeast, we will be able to gain new insights into prion function, both beneficial and detrimental, and their evolution. The Ctr4-based $\left[C T R^{+}\right]$prion identified here is a first step towards establishing $S$. pombe as a model system for this unique form of protein-based inheritance which may be much more widespread than suggested by the low number of species in which prions have been described and studied so far.

\section{MATERIALS AND METHODS}

\section{Yeast strains, plasmids, and growth conditions}

The $S$. pombe reference strain of the Bioneer deletion collection, ED668 $h^{+}$ade6-M216 ura4-D18 leu1-32 [76] was used to study overexpression of $S$. cerevisiae Sup35 (using the S. pombe nmt1 promoter on the PREP41 vector in the absence of thiamine [77]) and for protein transformations. S. cerevisiae $\left[\mathrm{PSI}^{+}\right]$and $[\mathrm{psi}]$ strain derivatives of 74D-694 (MATa ade1-14 trp1-289 his3-200 ura3-52 leu2-3,112, [PIN $\left.{ }^{+}\right]$) were used [48]. The $972 h^{-}$S. pombe strain was used for genetic crosses. The Ctr4-YFP overexpression strain was obtained from the overexpression ORFeome library [54]. The SUP35 ORF was amplified from the [psi] S. cerevisiae strain and cloned into the BamHI and Smal cloning sites of the pREP41-GFP vector. The hsp104 gene was deleted in S. pombe using the natMX6 cassette [78]. Tetrads were dissected with a Singer MSM 400 micromanipulator. The $c t r 4 \Delta$ single mutant $(h+$ his7-366 leu1-32 ura4-D18

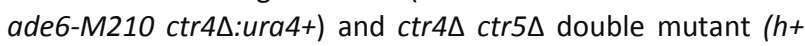

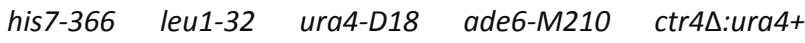
ctr5 $\Delta: K A N r)$, along with the wild-type control strain FY435 $(h+$ his7-366 leu1-32 ura4- $\Delta 18$ ade6-M210) were a kind gift from Dr Simon Labbé.

Yeast extract with supplements (YES) medium was used for most experiments, except for certain conditions, e.g. to maintain plasmids in growing cells or to support growth of ctr4 $\Delta$ mutants, where Edinburgh minimal medium (EMM), with supplements if indicated, was used instead. For oxidative-stress sensitivity assays, we spotted 5 -fold serial dilutions of $2 \times 10^{5}$ cells onto EMM plates (control) and spotted $2 \times 10^{5}$ cells across EMM plates containing 0 to $2.5 \mathrm{mM} \mathrm{H}_{2} \mathrm{O}_{2}$, obtained by combining slanted EMM agar and EMM agar plus 2.5 $\mathrm{mM} \mathrm{H}_{2} \mathrm{O}_{2}$ (Figure $4 \mathrm{C}$; all these EMM media contained adenine, uracil, leucine and histidine supplements), or spotted four 10fold serial dilutions $\left(\mathrm{OD}_{600} 1,0.1,0.01,0.001\right)$ onto YES plates with or without $2 \mathrm{mM} \mathrm{H}_{2} \mathrm{O}_{2}$ (Figure 5). Alternatively, growth was monitored in a Biolector microfermentor as previously described [79], using $1 \mathrm{mM} \mathrm{H}_{2} \mathrm{O}_{2}$ and exponential phase cultures set to $\mathrm{OD}_{600} \sim 0.15$ at the start of the experiment (Figure 4A). Viability was determined after exponential phase cultures were diluted to $\mathrm{OD}_{600} 0.003$, with or without adding $\mathrm{H}_{2} \mathrm{O}_{2}$ to $0.5 \mathrm{mM}$; after incubation for $24 \mathrm{~h}$ at $32^{\circ} \mathrm{C}$, cells were plated onto YES agar (Figure 4B). To eliminate prions, single colonies were successively streaked onto three subsequent YES plates containing $3 \mathrm{mM} \mathrm{GdnHCl}$. Single colonies were then picked from the last plate for experimental analyses.

\section{Protein analyses}

Protein extraction and subcellular fractionation were performed as described previously [58], with some modifications. Exponential phase cultures $(40 \mathrm{ml})$ were centrifuged at 4000 rpm for $3 \mathrm{~min}$ to collect cell pellets which were washed once in $1 \mathrm{ml}$ lysis buffer containing $10 \mathrm{mM}$ potassium buffer $\mathrm{pH}$ 7.5, $250 \mathrm{mM} \mathrm{NaCl}, 2 \mathrm{mM}$ PMSF, 1 tablet $/ 10 \mathrm{ml}$ mini protease inhibitor cocktail (Roche). Cell pellets were re-suspended in 400 $\mu \mathrm{l}$ of lysis buffer, and $50 \mu$ l glass beads ( $0.5 \mathrm{~mm}$, Sigma) were added to break cells in a bead beater for five $40 \mathrm{sec}$ cycles with samples being left on ice for 2 min between cycles. Cell debris was removed by centrifugation at $5000 \mathrm{rpm}$ for $5 \mathrm{~min}$ at $4^{\circ} \mathrm{C}$, and the supernatant ('total protein extract') was centrifuged at $20,000 \times \mathrm{g}$ for $45 \mathrm{~min}$ to separate soluble from insoluble fractions. The pellets were then re-suspended in $60 \mu \mathrm{l}$ of lysis buffer ('insoluble fraction') for dot blot analysis ( $5 \mu$ l spotted on to nitrocellulose membrane) and for protein transformations ( $20 \mu \mathrm{l}$ used). For proteinase $\mathrm{K}$ (PK) treatment, 2 or 5 $\mu \mathrm{g}$ of PK was added to $30 \mu \mathrm{l}$ of total protein extract and incubated at $37^{\circ} \mathrm{C}$ for $30 \mathrm{~min}$. To terminate the PK reaction, $5 \mathrm{mM}$ of PMSF was added, and samples were run on SDS-PAGE for western blotting using standard protocols. Analysis of Ctr4 aggregates by SDD-AGE was performed as described before [57]. For all western blots, an anti-GFP antibody (Santa Cruz Biotechnology) was used at 1:2000 and an anti-Cdc2 antibody (Sigma) at 1:5000, incubating overnight at $4^{\circ} \mathrm{C}$, followed by incubation with anti-rabbit or anti-mouse antibodies (Abcam), respectively, at 1:5000 for $1 \mathrm{~h}$ at room temperature.

\section{Protein transformation}

For transformation of proteins into fission or budding yeast, a standard protocol was used [80], and $20 \mu \mathrm{l}$ of insoluble protein fraction was prepared as described above, containing 0.025 units/ $\mu$ l benzonase to digest any nucleic acids present in the sample. Then, $20 \mathrm{ml}$ of exponential phase cell cultures were centrifuged, the cell pellets were washed and resuspended in $1 \mathrm{ml}$ of $0.1 \mathrm{M}$ lithium acetate (LiAc). For each transformation, we used $100 \mu \mathrm{l}$ of cells, adding $260 \mu \mathrm{l}$ of $40 \%$ PEG/0.1 M LiAc mix, $20 \mu \mathrm{l}$ of insoluble cell extract prepared as above, and the pRS416 [81] and pREP42 [77] plasmids for $S$. cerevisiae and $S$. pombe, respectively. This transformation mix was incubated at $30^{\circ} \mathrm{C}$ for $1 \mathrm{~h}$, after which $43 \mu \mathrm{l}$ of prewarmed DMSO was added, followed by heat shock at $42^{\circ} \mathrm{C}$ for $5 \mathrm{~min}$. Pellets were collected and washed once in $1 \mathrm{ml}$ of sterile water, re-suspended in $500 \mu \mathrm{l}$ of sterile water, and $250 \mu \mathrm{l}$ of cells were then plated on EMM agar selective medium. 


\section{ACKNOWLEDGEMENTS}

We thank Simon Labbé for strains and helpful discussions, and Antonia Lock for comments on the manuscript. This work was supported by a Wellcome Trust Senior Investigator Award (grant \# 095598/Z/11/Z), a Royal Society Wolfson Research Merit Award to J.B, and a Biotechnology and Biological Sciences Research Council grant (BB/J000191/1) and a Leverhulme Trust Research Fellowship (RF-2012-365) awarded to MFT.

\section{SUPPLEMENTAL MATERIAL}

All supplemental data for this article are available online at www.microbialcell.com.

\section{CONFLICT OF INTEREST}

The authors declare that they have no conflicts of interest.

\section{REFERENCES}

1. Prusiner SB (1982). Novel proteinaceous infectious particles cause scrapie. Science 216(4542): 136-144.

2. Liebman SW, Chernoff YO (2012). Prions in yeast. Genetics 191(4): 1041-1072.

3. Chakrabortee S, Kayatekin C, Newby GA, Mendillo ML, Lancaster A, Lindquist $S$ (2016). Luminidependens (LD) is an Arabidopsis protein with prion behavior. Proc Natl Acad Sci USA 113(21): 6065-6070.

4. Imran M, Mahmood S (2011). An overview of human prion diseases. Virology J 8:559.

5. Aguilar-Calvo P, Garcia C, Espinosa JC, Andreoletti O, Torres JM (2015). Prion and prion-like diseases in animals. Virus Res 207(82-93.

6. Schmitz M, Dittmar K, Llorens F, Gelpi E, Ferrer I, Schulz-Schaeffer WJ, Zerr I (2016). Hereditary Human Prion Diseases: an Update. Mol Neurobiol [Epub ahead of print]

7. Morales R, Callegari K, Soto C (2015). Prion-like features of misfolded Abeta and tau aggregates. Virus Res 207:106-112.

8. Collinge J (2016). Mammalian prions and their wider relevance in neurodegenerative diseases. Nature 539(7628): 217-226.

9. Smethurst P, Sidle KC, Hardy J (2015). Review: Prion-like mechanisms of transactive response DNA binding protein of $43 \mathrm{kDa}$ (TDP-43) in amyotrophic lateral sclerosis (ALS). Neuropathol Appl Neurobiol 41(5): 578-597.

10. Pearce MM, Spartz EJ, Hong W, Luo L, Kopito RR (2015). Prion-like transmission of neuronal huntingtin aggregates to phagocytic glia in the Drosophila brain. Nat Comm 6: 6768.

11. Aguzzi A, Rajendran L (2009). The transcellular spread of cytosolic amyloids, prions, and prionoids. Neuron 64(6): 783-790.

12. Polymenidou M, Cleveland DW (2012). Prion-like spread of protein aggregates in neurodegeneration. J Exp Med 209(5): 889-893.

13. Chernova TA, Wilkinson KD, Chernoff YO (2014). Physiological and environmental control of yeast prions. FEMS Microbiol Rev 38(2): 326-344.

14. Halfmann R, Alberti S, Lindquist S (2010). Prions, protein homeostasis, and phenotypic diversity. Trends Cell Biol 20(3): 125-133.

15. Halfmann R, Lindquist S (2010). Epigenetics in the extreme: prions and the inheritance of environmentally acquired traits. Science 330(6004): 629-632.

\section{COPYRIGHT}

(C) 2016 Sideri et al. This is an open-access article released under the terms of the Creative Commons Attribution (CC BY) license, which allows the unrestricted use, distribution, and reproduction in any medium, provided the original author and source are acknowledged.

Please cite this article as: Theodora Sideri, Yoko Yashiroda, David A. Ellis, María Rodríguez-López, Minoru Yoshida, Mick F. Tuite \& Jürg Bähler (2016). The copper transport-associated protein Ctr4 can form prion-like epigenetic determinants in Schizosaccharomyces pombe. Microbial Cell 4(1): 16-28. doi: 10.15698/mic2017.01.552

16. True HL, Berlin I, Lindquist SL (2004). Epigenetic regulation of translation reveals hidden genetic variation to produce complex traits. Nature 431(7005): 184-187.

17. True HL, Lindquist SL (2000). A yeast prion provides a mechanism for genetic variation and phenotypic diversity. Nature 407(6803): 477483.

18. Alberti S, Halfmann R, King O, Kapila A, Lindquist S (2009). A systematic survey identifies prions and illuminates sequence features of prionogenic proteins. Cell 137(1): 146-158.

19. Sideri TC, Koloteva-Levine N, Tuite MF, Grant CM (2011). Methionine oxidation of Sup35 protein induces formation of the [PSI+] prion in a yeast peroxiredoxin mutant. J Biol Chem 286(45): 38924-38931.

20. Sideri TC, Stojanovski K, Tuite MF, Grant CM (2010). Ribosomeassociated peroxiredoxins suppress oxidative stress-induced de novo formation of the [PSI+] prion in yeast. Proc Natl Acad Sci USA 107(14): 6394-6399.

21. Doronina VA, Staniforth GL, Speldewinde SH, Tuite MF, Grant CM (2015). Oxidative stress conditions increase the frequency of de novo formation of the yeast [PSI+] prion. Mol Microbiol 96(1): 163-174.

22. Tyedmers J, Madariaga ML, Lindquist S (2008). Prion switching in response to environmental stress. PLoS Biol 6(11): e294.

23. Dalstra HJ, van der Zee R, Swart K, Hoekstra RF, Saupe SJ, Debets AJ (2005). Non-mendelian inheritance of the HET-s prion or HET-s prion domains determines the het-S spore killing system in Podospora anserina. Fungal Genet Biol 42(10): 836-847.

24. Douglas PM, Treusch S, Ren HY, Halfmann R, Duennwald ML, Lindquist S, Cyr DM (2008). Chaperone-dependent amyloid assembly protects cells from prion toxicity. Proc Natl Acad Sci USA 105(20): 72067211.

25. Liu Y, Wei H, Qu J, Wang J, Hung T (2011). Prefibrillar aggregates of yeast prion Sup35NM and its variant are toxic to mammalian cells. Neurol Sci 32(6): 1147-1152.

26. Summers DW, Douglas PM, Ren HY, Cyr DM (2009). The type I Hsp40 Ydj1 utilizes a farnesyl moiety and zinc finger-like region to suppress prion toxicity. J Biol Chem 284(6): 3628-3639.

27. Eaglestone SS, Cox BS, Tuite MF (1999). Translation termination efficiency can be regulated in Saccharomyces cerevisiae by environmental stress through a prion-mediated mechanism. EMBO J 18(7): 1974-1981. 
28. Holmes DL, Lancaster AK, Lindquist S, Halfmann R (2013). Heritable remodeling of yeast multicellularity by an environmentally responsive prion. Cell 153(1): 153-165.

29. Halfmann R, Jarosz DF, Jones SK, Chang A, Lancaster AK, Lindquist $S$ (2012). Prions are a common mechanism for phenotypic inheritance in wild yeasts. Nature 482(7385): 363-368.

30. Aamodt K, Abel N, Abeysekara U, Abrahantes Quintana A, Abramyan A, Adamova D, Aggarwal MM, Aglieri Rinella G, Agocs AG, Aguilar Salazar S, Ahammed Z, Ahmad A, Ahmad N, Ahn SU, Akimoto R, Akindinov A, Aleksandrov D, Alessandro B, Alfaro Molina R, Alici A, Almaraz Avina E, Alme J, Alt T, Altini V, Altinpinar S, Andrei C, Andronic A, Anelli G, Angelov V, Anson C, et al. (2010). Midrapidity antiprotonto-proton ratio in pp collisons at sqrt[s] $=0.9$ and $7 \mathrm{TeV}$ measured by the ALICE experiment. Phys Rev Lett 105(7): 072002

31. Cai X, Chen J, Xu H, Liu S, Jiang QX, Halfmann R, Chen ZJ (2014). Prion-like polymerization underlies signal transduction in antiviral immune defense and inflammasome activation. Cell 156(6): 12071222.

32. Ritz AM, Trautwein M, Grassinger F, Spang A (2014). The prion-like domain in the exomer-dependent cargo Pin2 serves as a trans-Golgi retention motif. Cell Rep 7(1): 249-260.

33. Guerin R, Turcotte C, Leroux A, Rokeach LA (2009). The epigenetic calnexin-independent state is induced in response to environmental changes. FEMS Yeast Res 9(8): 1250-1259.

34. Byrne LJ, Cole DJ, Cox BS, Ridout MS, Morgan BJ, Tuite MF (2009). The number and transmission of [PSI] prion seeds (Propagons) in the yeast Saccharomyces cerevisiae. PloS ONE 4(3): e4670.

35. Tuite MF, Serio TR (2010). The prion hypothesis: from biological anomaly to basic regulatory mechanism. Nat Rev Mol Cel Biol 11(12): 823-833.

36. Suzuki G, Shimazu N, Tanaka M (2012). A yeast prion, Mod5, promotes acquired drug resistance and cell survival under environmental stress. Science 336(6079): 355-359.

37. Brown JC, Lindquist S (2009). A heritable switch in carbon source utilization driven by an unusual yeast prion. Genes Dev 23(19): 23202332.

38. Harrison PM, Gerstein M (2003). A method to assess compositional bias in biological sequences and its application to prion-like glutamine/asparagine-rich domains in eukaryotic proteomes. Genome Biol 4(6): R40.

39. Chernoff YO, Lindquist SL, Ono B, Inge-Vechtomov SG, Liebman SW (1995). Role of the chaperone protein Hsp104 in propagation of the yeast prion-like factor [psi+]. Science 268(5212): 880-884.

40. Byrne L, Cox BS, Cole DJ, Ridout MS, Morgan BJ, Tuite MF (2007). Cell division is essential for elimination of the yeast [PSI+] prion by guanidine hydrochloride. Proc Natl Acad Sci USA 104(28): 1168811693.

41. Senechal P, Arseneault G, Leroux A, Lindquist S, Rokeach LA (2009). The Schizosaccharomyces pombe Hsp104 disaggregase is unable to propagate the [PSI] prion. PloS ONE 4(9): e6939.

42. Reidy M, Sharma R, Masison DC (2013). Schizosaccharomyces pombe disaggregation machinery chaperones support Saccharomyces cerevisiae growth and prion propagation. Eukaryot Cell 12(5): 739745.

43. Fiske $M$, White $M$, Valtierra S, Herrera S, Solvang K, Konnikova A, Debburman S (2011). Familial Parkinson's disease mutant E46K alphasynuclein localizes to membranous structures, forms aggregates, and induces toxicity in yeast models. ISRN Neurology 2011:521847.
44. Wickner RB, Edskes HK, Maddelein ML, Taylor KL, Moriyama H (1999). Prions of yeast and fungi. Proteins as genetic material. J Biol Chem 274(2): 555-558.

45. Tenreiro S, Munder MC, Alberti S, Outeiro TF (2013). Harnessing the power of yeast to unravel the molecular basis of neurodegeneration. J Neurochem 127(4): 438-452.

46. Fruhmann G, Seynnaeve D, Zheng J, Ven K, Molenberghs S, Wilms T, Liu B, Winderickx J, Franssens V (2016). Yeast buddies helping to unravel the complexity of neurodegenerative disorders. Mech Ageing Dev [Epub ahead of print]

47. Zhou P, Derkatch IL, Liebman SW (2001). The relationship between visible intracellular aggregates that appear after overexpression of Sup35 and the yeast prion-like elements [PSI(+)] and [PIN(+)]. Mol Microbiol 39(1): 37-46.

48. Ferreira PC, Ness F, Edwards SR, Cox BS, Tuite MF (2001). The elimination of the yeast [PSI+] prion by guanidine hydrochloride is the result of Hsp104 inactivation. Mol Microbiol 40(6): 1357-1369.

49. Lancaster AK, Nutter-Upham A, Lindquist S, King OD (2014). PLAAC: a web and command-line application to identify proteins with prion-like amino acid composition. Bioinformatics 30(17): 2501-2502.

50. Bitton DA, Schubert F, Dey S, Okoniewski M, Smith GC, Khadayate S, Pancaldi V, Wood V, Bähler J (2015). AnGeLi: A Tool for the Analysis of Gene Lists from Fission Yeast. Front Genet 6: 330.

51. Buchan DW, Minneci F, Nugent TC, Bryson K, Jones DT (2013). Scalable web services for the PSIPRED Protein Analysis Workbench. Nucleic Acids Res 41(Web Server issue): W349-357.

52. Chen CY, Rojanatavorn K, Clark AC, Shih JC (2005). Characterization and enzymatic degradation of Sup35NM, a yeast prion-like protein. Protein Science 14(9): 2228-2235.

53. Silva CJ, Vazquez-Fernandez E, Onisko B, Requena JR (2015). Proteinase $\mathrm{K}$ and the structure of $\operatorname{PrP}(\mathrm{Sc})$ : The good, the bad and the ugly. Virus Res 207:120-126.

54. Matsuyama A, Arai R, Yashiroda $Y$, Shirai A, Kamata A, Sekido S, Kobayashi $Y$, Hashimoto A, Hamamoto M, Hiraoka $Y$, Horinouchi S, Yoshida $M$ (2006). ORFeome cloning and global analysis of protein localization in the fission yeast Schizosaccharomyces pombe. Nat Biotechnol 24(7): 841-847.

55. Labbé S, Pena MM, Fernandes AR, Thiele DJ (1999). A coppersensing transcription factor regulates iron uptake genes in Schizosaccharomyces pombe. J Biol Chem 274(51): 36252-36260.

56. Cohen A, Ross L, Nachman I, Bar-Nun S (2012). Aggregation of polyQ proteins is increased upon yeast aging and affected by Sir2 and Hsf1: novel quantitative biochemical and microscopic assays. PloS ONE 7(9): e44785.

57. Alberti S, Halfmann R, Lindquist S (2010). Biochemical, cell biological, and genetic assays to analyze amyloid and prion aggregation in yeast. Methods Enzymol 470: 709-734.

58. Ness F, Ferreira P, Cox BS, Tuite MF (2002). Guanidine hydrochloride inhibits the generation of prion "seeds" but not prion protein aggregation in yeast. Mol Cell Biol 22(15): 5593-5605.

59. Zenthon JF, Ness F, Cox B, Tuite MF (2006). The [PSI+] prion of Saccharomyces cerevisiae can be propagated by an Hsp104 orthologue from Candida albicans. Eukaryot Cell 5(2): 217-225.

60. Staniforth GL, Tuite MF (2012). Fungal prions. Prog Mol Biol Transl Sci 107: 417-456.

61. Chen D, Wilkinson CR, Watt S, Penkett CJ, Toone WM, Jones N, Bähler J (2008). Multiple pathways differentially regulate global oxidative stress responses in fission yeast. Mol Biol Cell 19(1): 308-317. 
62. Beaudoin J, Laliberte J, Labbe S (2006). Functional dissection of Ctr 4 and $\mathrm{Ctr} 5$ amino-terminal regions reveals motifs with redundant roles in copper transport. Microbiology 152(Pt 1): 209-222.

63. Tuite MF (2015). Yeast prions: Paramutation at the protein level? Semin Cell Dev Biol 44: 51-61.

64. Saupe SJ (2011). The [Het-s] prion of Podospora anserina and its role in heterokaryon incompatibility. Semin Cell Dev Biol 22(5): 460468.

65. Turcotte C, Roux A, Beauregard PB, Guerin R, Senechal P, Hajjar F, Rokeach LA (2007). The calnexin-independent state does not compensate for all calnexin functions in Schizosaccharomyces pombe. FEMS Yeast Res 7(2): 196-208.

66. Edskes HK, Khamar HJ, Winchester CL, Greenler AJ, Zhou A, McGlinchey RP, Gorkovskiy A, Wickner RB (2014). Sporadic distribution of prion-forming ability of Sup $35 p$ from yeasts and fungi. Genetics 198(2): 605-616.

67. Beaudoin J, Thiele DJ, Labbe S, Puig S (2011). Dissection of the relative contribution of the Schizosaccharomyces pombe Ctr4 and Ctr5 proteins to the copper transport and cell surface delivery functions. Microbiology 157(Pt 4): 1021-1031.

68. Ioannoni R, Beaudoin J, Mercier A, Labbe S (2010). Copperdependent trafficking of the Ctr4-Ctr5 copper transporting complex. PloS ONE 5(8): e11964.

69. Plante S, Ioannoni R, Beaudoin J, Labbe S (2014). Characterization of Schizosaccharomyces pombe copper transporter proteins in meiotic and sporulating cells. J Biol Chem 289(14): 10168-10181.

70. Deshpande GP, Hayles J, Hoe KL, Kim DU, Park HO, Hartsuiker E (2009). Screening a genome-wide $S$. pombe deletion library identifies novel genes and pathways involved in genome stability maintenance. DNA Repair 8(5): 672-679.

71. Jarosz DF, Lancaster AK, Brown JC, Lindquist S (2014). An evolutionarily conserved prion-like element converts wild fungi from metabolic specialists to generalists. Cell 158(5): 1072-1082.
72. Chernoff YO, Kiktev DA (2016). Dual role of ribosome-associated chaperones in prion formation and propagation. Curr Genet 62(4): 677-685.

73. Chakrabortee S, Byers JS, Jones S, Garcia DM, Bhullar B, Chang A, She R, Lee L, Fremin B, Lindquist S, Jarosz DF (2016). Intrinsically disordered proteins drive emergence and inheritance of biological traits. Cell 167(2): 369-381 e312.

74. Tuite MF (2016). Remembering the past: a new form of proteinbased inheritance. Cell 167(2): 302-303.

75. Halfmann R, Wright JR, Alberti S, Lindquist S, Rexach M (2012). Prion formation by a yeast GLFG nucleoporin. Prion 6(4): 391-399.

76. Kim DU, Hayles J, Kim D, Wood V, Park HO, Won M, Yoo HS, Duhig T, Nam M, Palmer G, Han S, Jeffery L, Baek ST, Lee H, Shim YS, Lee M, Kim L, Heo KS, Noh EJ, Lee AR, Jang YJ, Chung KS, Choi SJ, Park JY, Park Y, Kim HM, Park SK, Park HJ, Kang EJ, Kim HB, et al. (2010). Analysis of a genome-wide set of gene deletions in the fission yeast Schizosaccharomyces pombe. Nat Biotechnol 28(6): 617-623.

77. Basi G, Schmid E, Maundrell K (1993). TATA box mutations in the Schizosaccharomyces pombe nmt1 promoter affect transcription efficiency but not the transcription start point or thiamine repressibility. Gene 123(1): 131-136.

78. Sato M, Dhut S, Toda T (2005). New drug-resistant cassettes for gene disruption and epitope tagging in Schizosaccharomyces pombe. Yeast 22(7): 583-591.

79. Rallis C, Lopez-Maury L, Georgescu T, Pancaldi V, Bähler J (2014). Systematic screen for mutants resistant to TORC1 inhibition in fission yeast reveals genes involved in cellular ageing and growth. Biol Open 3(2): 161-171.

80. Beach D, Nurse $P$ (1981). High-frequency transformation of the fission yeast Schizosaccharomyces pombe. Nature 290(5802): 140142.

81. Sikorski RS, Hieter P (1989). A system of shuttle vectors and yeast host strains designed for efficient manipulation of DNA in Saccharomyces cerevisiae. Genetics 122(1): 19-27. 